GABA-GABA: Jurnal Pengabdian Masyarakat dalam bidang Pendidikan Bahasa dan Seni

Vol. 1 No. 2, November 2021, Hal 43-48

e-ISSN: 2797-8494

\title{
KULIAH UMUM PENGEMBANGAN PEMBELAJARAN BERBASIS TEKS DALAM PROGRAM BAHASA INDONESIA BAGI PENUTUR ASING (BIPA) DI UNIVERSITAS PATTIMURA
}

\author{
Grace Somelok $^{1}$, Leonora Farilyn Pesiwarissa ${ }^{2}$ \\ Pendidikan Bahasa dan Sastra Indonesia, FKIP Universitas Pattimura \\ email : gracedesilo@gmail.com \\ Pendidikan Bahasa dan Sastra Indonesia, FKIP Universitas Pattimura \\ email : lpesiwarissa@gmail.com
}

\begin{abstract}
Abstrak
Pembelajaran BIPA (Bahasa Indonesia bagi Penutur Asing) merupakan suatu program yang multidimensional, yang tidak hanya berkaitan dengan program pendidikan dan pengajaran bahasa Indonesia, melainkan juga berkaitan erat dengan peningkatan kerja sama global, pemahaman antarbudaya, peningkatan kerja sama ekonomi, mendorong dan memperkuat pariwisata berbasis budaya, bahasa dan sastra. Dalam pelaksanaannya, metode pembelajaran akan menjadi sumber kesulitan tersendiri, tentu saja karena terdapat perbedaan signifikan antara praktik pengajaran bahasa Indonesia kepada orang asing, sebagai bahasa kedua. Pengajar BIPA biasanya akan mengalami kesulitan mengenali potensi siswa, sekaligus merumuskan langkah-langkah yang bersifat metodologis untuk memecahkan persoalan. Sehingga pembelajaran berbasis teks (Genre Based Approach) dapat menjadi salah satu alternatif penting untuk diajukan sebagai metode pembelajaran yang sesuai dengan kebutuhan siswa.

Kegiatan dilaksanakan dengan format penyuluhan dalam bentuk kuliah umum kepada masyarakat umum, khususnya para pengajar dan pegiat BIPA, mahasiswa mata kuliah BIPA, serta para pemangku kepentingan dari institusi lain di Maluku. Narasumber kegiatan berasal dari tim pelaksana dan ahli lainnya yang dianggap sesuai dengan kebutuhan materi dan rekam jejak ahli. Kegiatan dilaksanakan secara virtual lewat aplikasi Zoom. Luaran kegiatan berupa rekaman video kegiatan, artikel berita di media daring malukuonline.com dan porosmaluku.com, serta artikel PKM pada jurnal nasional.
\end{abstract}

Kata Kunci: BIPA, pembelajaran berbasis teks, kuliah umum 


\begin{abstract}
BIPA (Indonesian learning for Foreign Speakers) is a multidimensional program, which is not only related to education and teaching programs Indonesian, but also closely related to increasing global cooperation, intercultural understanding, increasing economic cooperation, and encouraging and strengthening tourism based on culture, language and literature. In its implementation, the learning method will be a source of difficulties in itself, of course because there is a significant difference between the practice of teaching Indonesian to foreigners, as a second language. Then, BIPA teachers will usually have difficulty recognizing the potential of students, as well as formulating methodological steps to solve problems. In this context, text-based learning (Genre Based Approach) can be one of the important and viable alternatives to be proposed for the sake of expanding insights in learning methods that suit the needs of students.

The activity was carried out in the extension format in the form of public lectures to the general public who were interested in following, especially BIPA teachers and activists, BIPA course students, as well as stakeholders from other institutions in Maluku. The source of the activity comes from the managing team and other experts who are considered in accordance with the material needs and expert track record. The activity is carried out virtually through the Zoom application. External activities in the form of video recordings of activities, news articles in online media malukuonline.com and porosmaluku.com, as well as PKM articles in national journals have not been accredited, namely Gaba-Gaba Journal, published by the Department of Language and Arts Education, FKIP, Pattimura University.
\end{abstract}

Keywords: BIPA, genre based approach, public lectures

\title{
1. PENDAHULUAN
}

Pembelajaran Bahasa Indonesia untuk Penutur Asing (BIPA) adalah program yang berkaitan dengan internasionalisasi bahasa Indonesia, sekaligus sebagai sarana untuk memperkenalkan kebudayaan Indonesia kepada dunia luar. BIPA juga merupakan suatu program yang multidimensional, yang tidak hanya berkaitan dengan program pendidikan dan pengajaran bahasa Indonesia, melainkan juga berkaitan erat dengan peningkatan kerja sama global, pemahaman antarbudaya, peningkatan kerja sama ekonomi, maupun mendorong dan memperkuat pariwisata berbasis budaya, bahasa dan sastra, sehingga pada akhirnya akan memberikan dampak positif terhadap peningkatan perekonomian negara.

Menurut data Kemendikbud (https://lldiktil.ristekdikti.go.id/details/apps/2099), hingga saat ini, terdapat 420 lembaga yang menyediakan program BIPA yang tersebar di 29 negara. Jumlah ini akan bertambah dengan adanya program BIPA yang dilayani secara mandiri oleh pengajar-pengajar yang tidak berafiliasi kepada lembaga manapun, tetapi memiliki kepedulian dan semangat yang tinggi dalam mengembangkan dan mendukung internasionalisasi bahasa Indonesia. Pengajar-pengajar yang dimaksudkan, yakni yang menjadi pengajar secara privat dan melayani pemelajar yang juga memiliki tujuan-tujuan masing-masing dalam mempelajari bahasa Indonesia.

Keberadaan program BIPA di Maluku telah dirintis sejak berdirinya BIPA Universitas Pattimura pada tahun 2015. Setelah itu, secara perlahan-lahan, minat para pegiat di bidang pembelajaran bahasa Indonesia terhadap BIPA makin tumbuh. Sampai hari ini sudah ada 
beberapa pengajar BIPA mandiri yang tidak berafiliasi ke lembaga tertentu. Di samping itu, ada beberapa lembaga telah ikut merintis jalan untuk menyediakan layanan program BIPA sesuai potensi masing-masing, yakni STKIP Hatta-Sjahrir di Banda Neira, dan Universitas Iqra, Buru.

Ada perbedaan antara BIPA dengan bidang lainnya, yaitu peserta yang mengikuti kursus dan pelatihan ini merupakan warga negara asing atau warga negara Indonesia yang tidak bisa berbahasa Indonesia. Peserta didik ini mempelajari bahasa Indonesia untuk berbagai tujuan, di antaranya dapat berinteraksi dan berkomunikasi dengan menggunakan bahasa Indonesia, bukan untuk mendapatkan keahlian dalam bidang pekerjaan. Menurut Permendibud Nomor 27 Tahun 2017, Profil lulusan program kursus dan pelatihan BIPA ini diharapkan mempunyai penguasaan berbahasa Indonesia lisan dan tulis yang meliputi empat aspek keterampilan berbahasa (mendengarkan, berbicara, membaca, dan menulis).

Sudah tentu, mengajarkan bahasa Indonesia kepada penutur asing adalah hal yang tidak mudah. Demikian pula pendekatan, metode, serta media yang digunakan haruslah bersifat konstruktif dan menciptakan pembelajaran yang bermakna bagi pemelajar. Mengingat bahwa metode pembelajaran akan menjadi sumber kesulitan tersendiri, tentu saja karena terdapat perbedaan signifikan antara praktik pengajaran bahasa Indonesia kepada orang asing, sebagai bahasa kedua. Kedua, pengajar BIPA biasanya akan mengalami kesulitan mengenali potensi siswa, sekaligus merumuskan langkah-langkah yang bersifat metodologis untuk memecahkan persoalan.

Salah satu metode pembelajaran yang dipandang tepat dan sesuai dengan kebutuhan pemelajar dan pengajar, sebagaimana yang telah dijelaskan adalah pembelajaran berbasis teks (Text- Based Instruction / Genre-Based Instruction). Emilia (2011:15) menyatakan bahwa Pembelajaran Berbasis Teks dilakukan pada satuan teks dengan tujuan untuk melaksanakan berbagai tindakan komunikatif secara bermakna, dengan menggunakan atau terkait dengan teksteks yang bermanfaat bagi kehidupan peserta didik, secara reseptif dan produktif, secara lisan maupun tulis, di berbagai konteks yang relevan dengan kehidupan siswa, dalam bentuk kegiatan berbicara, menyimak, membaca, dan menulis yang terintegrasi secara alami dalam berbagai kegiatan komunikatif yang bermakna. Hal ini berarti bahwa teks dipelajari bukan sebagai sasaran akhir, tetapi sebagai alat untuk melakukan berbagai aktivitas terkait dengan dengan kehidupan nyata.

Secara ringkas, tahapan pembelajaran berbasis teks terdiri atas (1) building knowledge of the field, (2) modelling, (3) joint negotiation of a text, dan (4) independent instruction of a text. Pada tahap building knowledge of the field dilakukan penentuan pola tata bahasa yang akan diajarkan, kosakata target yang sesuai dengan teks serta pengelompokan perbandingan lintas budaya. Pada tahap modelling dilakukan pemetaan terhadap contoh-contoh sebuah genre teks. Selain itu, dipetakan pula latihan berupa mengonstruksi ulang genre teks yang telah diajarkan. Pada tahap joint negotiation of a text dilakukan pemetaan berupa latihan mengonstruksi teks baru bergenre sama berdasarkan tata bahasa serta genre teks yang telah dipelajari dalam bentuk individu maupaun kelompok. Selanjutnya, pada tahap tahap terakhir yakni independent instruction of a text, dilakukan pemetaan berupa penugasan untuk merancang teks berdasarkan genre tertentu.

Tujuan pembelajaran berbasis teks (Text- Based Instruction / Genre-Based Instruction) adalah untuk mempersiapkan pemelajar memasuki realitas penggunaan bahasa dengan berpusat pada penggunaan bahasa untuk mencapai berbagai macam tujuan, misalnya: membuat laporan percobaan, bercerita, atau mengonstruksi penjelasan. Selain itu, pembelajaran berbasis teks juga bertujuan agar pemelajar dapat memahami ilmu pengetahuan melalui teks 
yang dikonstruksikan dan diberikan kepada siswa sesuai dengan tujuan sosial tertentu. Pada akhirnya, hal itu juga mendorong pemelajar memahami perkembangan kognitif dan mental untuk menyelesaikan masalah kehidupan nyata dengan cara mengonstruksikan cara berpikir kritis. Keunggulan pembelajaran berbasis teks dibandingkan dengan metode pembelajaran bahasa lainnya yaitu adanya fakta bahwa pembelajaran ini memungkinkan pemelajar untuk mempelajari suatu bahasa secara jelas dan eksplisit. Selain itu, pembelajaran berbasis teks mampu mengembangkan kemampuan berpikir kritis siswa karena pembelajaran ini berorientasi pada keterampilan membaca dan menulis sebagai puncak konstruksinya. Kedua keterampilan berbahasa tersebut tentu menjadi media yang paling sesuai dalam mengonstruksikan kemampuan siswa untuk berpikir kritis..

Berdasarkan uraian tersebut, pengetahuan pengajar dan pegiat BIPA di Maluku mengenai pembelajaran berbasis teks belum cukup memadai. Hal ini berdasarkan pengamatan yang telah dilakukan terhadap realitas pembelajaran BIPA dan kesulitan-kesulitan yang dihadapi oleh pengajar yang diidentifikasi dalam berbagai kesempatan diskusi dan pertemuan, baik formal, maupun informal. Dengan demikian, diperlukan adanya upaya yang terencana dan sistematis untuk mengenalkan pembelajaran berbasis teks sebagai solusi penting untuk memperkuat dasar pedagogis para pengajar dan pegiat BIPA. Berdasarkan hal tersebut, maka Kuliah Umum Pengembangan Pembelajaran Berbasis Teks dalam Program Bahasa Indonesia bagi Penutur Asing (BIPA) di Universitas Pattimura dipandang penting untuk dilakukan sebagai suatu bentuk pengabdian kepada masyarakat. Kegiatan ini direncanakan akan melibatkan para pemangku kepentingan, yakni: para pengajar BIPA, pegiat BIPA, para ahli pembelajaran BIPA, Asosiasi Pengajar dan Pegiat BIPA Cabang Maluku, serta pihak-pihak lain, terutama institusi pendidikan tinggi lainnya yang berminat untuk membuka program BIPA demi pengembangan institusi. Kegiatan kuliah umum ini diharapkan dapat memperkaya pengetahuan para pemelajar dan pegiat BIPA mengenai pembelajaran bahasa yang berbasis teks, serta dapat meningkatkan kreativitas mereka dalam menyiapkan model dan metode yang tepat untuk mengajarkan bahasa Indonesia bagi penutur asing. Tidak menutup kemungkinan hasil dari kuliah umum ini juga dapat memperkaya para guru bahasa dengan metode-metode yang tepat dan menarik untuk digunakan dalam mengajar bahasa kepada siswa-siswanya. Tujuan jangka panjang kegiatan PKM ini adalah untuk menyiapkan sumber-sumber daya yang kompeten untuk mengenalkan bahasa Indonesia sekaligus berbagai ragam budayanya kepada dunia internasional.

\section{METODE PELAKSANAAN PENGABDIAN}

Secara metodologis, kegiatan PKM ini digambarkan dalam urutan kerja sebagai berikut:

a) Tahap Awal

Pada tahap awal ini, dilakukan penelusuran yang lebih komprehensif tentang pengajar dan pegiat BIPA di Maluku, melakukan pendaftaran peserta kuliah umum, mencari narasumber yang sesuai. Narasumber diupayakan berasal dari pengajar BIPA/ahli pembelajaran BIPA, diutamakan yang berasal dari Universitas Pattimura. Sesudah menentukan narasumber dan materi-materi yang akan disajikan terkait dengan Pembelajaran Berbasis Teks dalam Program Bahasa Indonesia Bagi Penutur Asing ( BIPA ), maka dibuatlah flyer untuk disebarkan kepada mahasiswa maupun guru atau pegiat BIPA di Maluku, khususnya pada Universitas Pattimura Ambon, Selanjutnya, penentuan tanggal pelaksanaan kegiatan yang disepakati pada hari Jumat, 13 Agustus 2021 dan dilakukan secara daring atau online. 
Kapasitas peserta bengkel daring ini berjumlah 100 orang peserta baik dari kalangan dosen, guru, mahasiswa maupun pegiat BIPA di Maluku. Bengkel daring (PKM) ini dilaksanakan dengan menggunakan aplikasi zoom. Pada Pelaksanaan PKM ini, kami mengundang salah satu narasumber dari Universitas Katolik Indonesia Atmajaya, Jakarta yaitu Paulina Chandrasari Kusuma, M.Hum. untuk memberikan materi awal sebagai pembuka pada kegiatan PKM yang kami laksanakan, dengan judul "Pembelajaran Berbasis Teks dalam kerangka Merdeka Belajar kampus Merdeka”. Di samping narasumber utama, kami juga memberikan materi PKM terkait dengan "Pengembangan Pembelajaran Berbasis Teks dalam Program Bahasa Indonesia bagi Penutur Asing (BIPA) di Universitas Pattimura.

Kegiatan PKM ini bersumber dari DIPA Fakultas Keguruan dan Ilmu Pendidikan Universitas Pattimura, sebesar Lima Juta Rupiah ( Rp.5.000.000,-).

b) Tahap Pelaksanaan.

Pada tahapan pelaksanaan yakni pada Jumat. 13 Agustus 2021, para peserta mengikuti kuliah umum secara virtual melalui aplikasi Zoom dengan meeting ID 6619 8574, passcode PKM2021. Kuliah Umum dibuka oleh pimpinan jurusan dalam hal ini Ketua Jurusan Pendidikan Bahasa dan Seni, Dr H. Maruanaya, M.Ed. Kegiatan ini terbuka untuk umum, kepada pengajar/pegiat BIPA yang berminat mengikuti, terutama yang berasal dari berbagai kabupaten/kota di Provinsi Maluku sebagai wujud pengabdian kepada masyarakat yang dilakukan oleh Fakultas Keguruan dan Ilmu Pendidikan, Universitas Pattimura. Kegiatan PKM ini berlangsung dari pukul 15.00 WIT sampai dengan pukul 17.00 WIT.

c) Tahap Pelaporan

Tahapan ini meliputi evaluasi terhadap pelaksanaan kegiatan serta umpan balik terhadap tim pelaksana kegiatan, serta merancang strategi selanjutnya untuk keberlanjutan program. Laporan disampaikan kepada pimpinan fakultas, baik berupa laporan penggunaan anggaran kegiatan maupun laporan pelaksanaan kegiatan PKM.

d) Tahap Publikasi

Kegiatan PKM ini telah selesai dan laporan kegiatannya dimasukkan pada pihak fakultas dan kegiatan akhir dari PKM ini yaitu Publikasi jurnal ilmiah sekaligus untuk mempromosikan program BIPA di Maluku sebagai lahan potensial untuk pengembangan layanan pendidikan dan peningkatan kualitas institusional dan kompetensi pihak-pihak terkait.

\section{PEMBAHASAN}

Hasil yang dicapai dari kegiatan PKM dalam bentuk kuliah umum ini adalah para peserta yang mayoritas terdiri dari para pengajar dan pegiat BIPA, juga guru-guru bahasa seMaluku memiliki pengetahuan yang memadai mengenai pembelajaran berbasis teks, serta dapat mengaplikasikannya dalam pelaksanaan tugas dan tanggung jawab mereka sebagai pengajar BIPA maupun guru bahasa. Berbagai jenis model, metode dan media mengajar yang kreatif dan inovatif dalam pelaksanaan pembelajaran berbasis teks dapat mereka gunakan untuk mengajarkan bahasa dengan menarik, sehingga dapat menarik minat orang untuk belajar bahasa, terutama dalam memperkenalkan bahasa Indonesia di dunia internasional. 
Pembelajaran berbasis teks diharapkan dapat menjadi jawaban kegelisahan para pengajar dan pegiat BIPA selama ini dalam menggunakan metode yang tepat untuk mengajarkan bahasa Indonesia kepada penutur asing. Berbagai bentuk teks yang disesuaikan dengan konteks setempat memudahkan siswa memahami materi yang diajarkan. Model atau metode pembelajaran berbasis teks diharapkan dapat dilakukan oleh pemelajar dan pegiat BIPA dengan memanfaatkan teks-teks yang bermanfaat bagi kehidupan pemelajar secara reseptif dan produktif, secara lisan maupun tulis, di berbagai konteks yang relevan dengan kehidupan mereka, entah dalam bentuk kegiatan menyimak, berbicara, membaca, maupun menulis.

Selain pemelajar dan pegiat BIPA, materi kuliah umum ini pun dapat dimanfaatkan oleh guru dalam menerapkan metode yang tepat dan dekat dengan kehidupan siswa sehingga materi yang diberikan dapat lebih mudah diserap.

Para peserta kuliah umum yang sebagian besar terdiri dari pengajar dan pegiat BIPA, guru, serta mahasiswa terkesan puas dengan pelaksanaannya, dibuktikan dengan diskusidiskusi menarik sepanjang kegiatan yang membahas fenomena pembelajaran BIPA maupun bahasa pada umumnya, sehingga mendorong untuk dilakukannya kegiatan seperti ini di waktu-waktu berikutnya, guna saling memperkaya pengetahuan para pendidik, calon pendidik, dan pemerhati pendidikan. Tujuan dasarnya adalah meningkatkan kualitas pendidikan serta meningkatkan ketertarikan dunia internasional untuk lebih mengenal bahasa dan budaya Indonesia.

\section{PENUTUP}

Dari hasil pelaksanaan PKM dengan bertemakan pembelajaran berbasis teks ini, dapat kita simpulkan bahwa pengembangan pembelajaran Bahasa Indonesia berbasis teks sangat mempermudah pembelajar BIPA dalam mencerna materi yang diajarkan. Selain itu, pentingnya pengetahuan pengajar dan pegiat BIPA di Maluku dalam hal ini tentang pembelajaran berbasis teks untuk menambah khasanah proses pembelajaran BIPA bagi penutur asing. Berbagai media pembelajaran tradisional atau manual maupun digital dapat diaplikasikan ke dalam pembelajaran BIPA berbasis teks sesuai dengan tingkat level pembelajar.

\section{REFERENSI}

Arsyad Ashar.1997. Media Pembelajaran. Raja Grafindo Persada.Jakarta.

Emilia, Emi. 2011. Pendekatan Genre-based Approach dalam. Pengajaran Bahasa Inggris: Petunjuk Bagi Guru. Bandung: Rizqi Press.

Maharany, Elva Riezky. 2020. Pengembangan Silabus Pengajaran BIPA Berbasis Teks. Dimuat dalam Jurnal Pendidikan Bahasa dan Sastra Indonesia, Universitas Pendidikan Ganesha, volume 1 edisi 1. E-ISSN: 2614-2007, https://ejournal.undiksha.ac.id/ index.php/JJPBS

http://appbipa.or.id/unduh/Permendikbud\%20Nomor\%2027\%20Tahun\%202017.pdf https://lidikti1.ristekdikti.go.id/details/apps/2099 